Robert Smith

British Library

\title{
Introduction
}

The project I am going to outline here is a wide-ranging multi-national cooperative project. It is split into a series of sub-projects each of which tackles specific areas of CD-ROM and its use as a carrier of bibliographic data.

The project owes its beginning, to some degree, to an earlier cooperative project between the British Library and the Bibliothèque Nationale. Together the two national libraries specified and published a joint CD-ROM of bibliographic data (sub-sets of their respective national bibliographies). At the same time the Deutsche Bibliothek in Frankfurt was producing a pilot CD-ROM. The discs were complementary in many ways and a full evaluation was carried out and funded by the CEC. The results were presented in a workshop in Amsterdam in 1989.

One important result of the pilot discs and the evaluation exercise was the subsequent move to publication of their respective national bibliographies on CD-ROM by the UK, France and Germany.

More relevant to the subject of this paper today was the impetus which that pilot disc programme gave to the national libraries to look at practical ways of building on this successful cooperation and to cut a long story short, the current project was defined and agreed between seven national libraries; and generous funding was made available by the CEC under its IMPACT programme.

The libraries directly participating in the project are:

British Library, UK

Bibliothèque Nationale, France

Deutsche Bibliothek, Germany

Royal Library, The Netherlands

Royal Library, Denmark

Biblioteca Nazionale Centrale di Firenze, Italy

Biblioteca Nacional, Portugal

\section{Key Aims}

The key aims of the project are as follows:

i To promote better and easier access by more users to European national bibliographies

ii to promote economies in library cataloguing through an improved interchange of bibliographic records between European (and non-European) national libraries, irrespective of differing national MARC formats;

iii to develop shared approaches to strategies, applications and formats for bibliographic data on CD-ROM. 
The first two of those aims are very broad and quite ambitious; the time-frame of this project will really only allow us to set up mechanisms whereby we can measure in futrure how successful we have been in meeting those aims. We are concentrating on the third aim - the development of shared approaches - and we believe that this can be achieved and that it will facilitate the achievement of the others. Most of this paper therefore relates directly to this - the attempt to develop shared approaches to strategies, applications and formats for bibliographic data on CD-ROM.

Scope of the project

In order to tackle this aim we defined nine separate sub-projects (known as workpackages) all linking in to this and in many cases linking in with each other.

\section{Retrieval Interface}

The single most significant result of this project will be a broad-based specification for a retrieval interface intended for use with national bibliographic data on CD-ROM. A draft has already been produced and is being tested in the project on pilot CD-ROMs (described below).

\section{MARC Conversion}

One of the barriers to exchange of bibliographic records is the different MARC formats in use in European libraries. This project is seeking to develop microbased conversion software which will allow downloaded bibliographic records to be converted between different MARC formats. The project is considering the use of some public domain software - the "CCF Converter" developed at the University of British Columbia. Initial results look promising.

\section{Character Sets}

The objective of this project is to define a basic set of European characters following the requirements for data representation of major European languages and to make it practicable in the context of microcomputer technology. Some initial work has been carried out, including a survey of current practice in national libraries and some tentative recommendations have been made. As the project continues new developments have to be taken into account, particularly the likely adoption of UNICODE.

This project seeks to standardise on some basic terms used in the retrieval interface for CD-ROM applications. A table of commonly used terms has been produced in English and French and translations have been supplied by all participating libraries and others. This project is almost complete and will result in lists of common terms in English, French, German, Danish, Dutch, Italian, Portuguese, Swedish, Finnish and Spanish. The project also commissioned a report on the technical implications of holding multi-lingual files on a microcomputer.

\section{$5 \quad$ Links to Online Systems}

CD-ROM is by its nature not a tool for current information. National bibliographies on CD-ROM are, typically, updated four times a year. On the other hand online systems tend to be updated much more frequently. This project is looking at ways of linking CD-ROM to online systems as straightforwardly as possible so as to allow current information to be obtained online to supplement the information found on the CD-ROM. The main result 
of the project will be some pilot software which is currently under development. This will take searches from the $B N B$ on $C D-R O M$ and transfer them to the British Library's online service, BLAISE-LINE: and will also take searches from the French National Bibliography and transfer them to the French host Questel.

\section{Links to Local Library Systems}

One of the uses which national bibliographies on CD-ROM are put to is cataloguing - and in particular retrospective cataloguing. This project will produce a series of detailed case studies on the ways some libraries are using existing national bibliographies on CD-ROM for cataloguing and how the downloaded records interface with the local library system.

Menu systems/Compatibility

When this project was being developed incompatibility between different CDROM publications was a major issue and caused many problems. This project sought to identify such problems and propose solutions, in the form of menutype software. In the event many of the original problems no longer exist. A detailed study of CD-ROM applications was made and a minimum desired configuration was recommended to ensure compatible running of CD-ROMs. Recommendations were also made to assist with the choice of commercial menu software.

\section{Pilot CD-ROMs}

The major outputs from the project will be two CD-ROMs. These are both pilot discs and will test out some of the work done in other parts of the project. The first CD-ROM is a sub-set of four national bibliographies - from the Netherlands, Portugal, Denmark and Italy. It was produced by a bureau in Denmark and is undergoing an extensive evaluation. The second CD-ROM may use authoring software (intended for in-house production) and will be a combined database of bibliographic records from all seven participating national libraries. It will contain records of children's and youth literature. A further result of this project will be a detailed set of guidelines for production of a bibliographic CD-ROM, which will be published.

\section{Framework for exchange of records}

This project is considering the framework in which bibliographic records are exchanged within the EC. It is looking at legal implications, and the possible impact of the single market. A series of recommendations have been developed which are currently under discussion within the national libraries concerned.

\section{Summary of results of the project}

There follows a brief summary of some of the main deliverables of the project:

Report on access to and retrieval of MARC records in a CD-ROM environment Study of OPACs in relation to CD-ROM

Feasibility study into a micro-based MARC conversion program

Survey of current use of different character sets in bibliographic applications Report on range of translations used for functions associated with bibliographic CD-ROM applications - eg Help screens, indexes

Survey of existing CD-ROM products which incorporate links to online hosts Survey of currently available telecomms packages

Case studies on the use of CD-ROM for cataloguing in libraries 
Survey of the compatibility of principal CD-ROM products in libraries Report with profiles of the availability of national bibliographies in machine readable form

Guideline document for specification of CD-ROM production, to include critical decision points, timescales, costing criteria, etc.

Guide to the production of MARC bibliographic data on CD-ROM.

Report on legal issues and policy issues involved in the international transfer and usage of national bibliographic data.

These reports and surveys are being achieved by a combination of checking on the appropriate literature for any work already done in these areas and also by the preparation of new and original research by the participants in the project and/or by contracted consultants.

There are several kinds of prototype being developed during the course of the project, including:

Prototype linking software from a CD-ROM national bibliography to a remote online host

Prototype conversion software to allow conversion between different MARC formats

Two prototype CD-ROM publications to test out recommendations made as the project is pursued

Prototypes in the project are based on specifications drawn up by participants and/or contracted specialist consultants. The prototypes are being developed under contract by a variety of software developers and CD-ROM producers.

\section{Cooperation}

Part of the Commission's aim in funding this project is to encourage cooperation and initiate common approaches. Consequently each of the projects is carried out by a small working group drawn from the participating libraries and coordinated by one of them. The project as a whole is managed by the British Library. The BL administers the funding from the Commission and distributes it to other participants and to all subcontractors. It also coordinates, monitors and reports back to the CEC with the help of an Executive Committee on which all participating libraries are represented.

Individual projects (or workpackages) are "led" by one of the participating libraries with assistance from two or three of the others.

In all we have over twenty different people from seven countries working together. In addition to these working groups, some of the work is carried out under sub-contract by experts in various fields. So, for example, the report on MARC-based CD-ROM publications which was intended as part of the preparatory work for the development of a retrieval interface was carried out by a bureau in Denmark which has a great deal of experience with CD-ROMs - their use, their functionality and their actual production. In such cases there have to be close links between the sub-contracted company and one of the partners (in this case the Royal Library, Copenhagen) with whom the subcontract is made.

Cooperation is the key to the project; without it the project would not be happening at all and would certainly not have attracted funding from the Commission. It is seen in Luxembourg as a pilot project in more ways than one - the way the cooperative element is emphasised, down to workpackage level; the delegating of financial control to one of the partners; and the subject matter itself are regarded as preparation for the projects that will be run under the Action Plan for Libraries over the next few years. Experience gained in this project should, we hope, benefit all those who are making bids for funding in the years to come. 